\title{
Kinetics and Mechanism of Nucleophilic Displacement Reactions of Y-Substituted Phenyl Benzoates with Cyanide Ion ${ }^{\dagger}$
}

\author{
Song-I Kim, Eun-Hee Kim, and Ik-Hwan Um* \\ Department of Chemistry and Nano Science, Ewha Womans University, Seoul 120-750, Korea.*E-mail: ihum@ewha.ac.kr \\ Received September 22, 2009, Accepted January 5, 2010
}

\begin{abstract}
Second-order rate constants $\left(k_{\mathrm{CN}^{-}}\right)$have been measured for nucleophilic substitution reactions of Y-substituted phenyl benzoates (1a-r) with $\mathrm{CN}^{-}$ion in $80 \mathrm{~mol} \% \mathrm{H}_{2} \mathrm{O} / 20 \mathrm{~mol} \% \mathrm{DMSO}$ at $25.0 \pm 0.1{ }^{\circ} \mathrm{C}$. The Brønsted-type plot is linear with $\beta_{\mathrm{lg}}=-0.49$, a typical $\beta_{\mathrm{lg}}$ value for reactions reported to proceed through a concerted mechanism. Hammett plots correlated with $\sigma^{\circ}$ and $\sigma^{-}$constants exhibit many scattered points. In contrast, the Yukawa-Tsuno plot for the same reaction exhibits excellent linearity with $\rho_{Y}=1.37$ and $r=0.34$, indicating that a negative charge develops partially on the oxygen atom of the leaving aryloxide in the rate-determining step (RDS). Although two different mechanisms are plausible (i.e., a concerted mechanism and a stepwise pathway in which expulsion of the leaving group occurs at the RDS), the reaction has been concluded to proceed through a concerted mechanism on the basis of the magnitude of $\beta_{\lg }$ and $\rho_{\mathrm{Y}}$ values.
\end{abstract}

Key Words: Aryl benzoates, Brønsted-type plot, Hammett plot, Rate-determining step, Yukawa-Tsuno plot

\section{Introduction}

Reactions of carboxylic esters with amines have generally been reported to proceed through a stepwise mechanism. ${ }^{1}$ Curved Brønsted-type plots obtained for aminolyses of esters possessing a good leaving group (e.g., 2,4-dinitrophenoxide) have been taken as evidence for a stepwise mechanism with a change in rate-determining step (RDS). ${ }^{1}$ The RDS has been suggested to change from breakdown of a zwitterionic tetrahedral intermediate to its formation as the incoming amine becomes more basic than the leaving group by 4 to $5 \mathrm{p} K_{\mathrm{a}}$ units. ${ }^{1}$

In contrast, reactions of esters with anionic nucleophiles have not been completely understood. Williams and his coworkers concluded that acyl-group transfer reactions of 4-nitrophenyl acetate with a series of aryloxides proceed through a concerted mechanism on the basis of absence of a break (or curvature) in the Brønsted-type plot. ${ }^{2}$ The concerted mechanism has been supported through structure-reactivity correlations by Jencks, ${ }^{\text {a }}$ Rossi, $^{3 \mathrm{~b}}$ and Castro, ${ }^{3 \mathrm{c}}$ as well as kinetic isotope effect studies of Hengge $^{3 \mathrm{~d}}$ and Marcus analysis by Guthrie. ${ }^{3 \mathrm{e}}$ However, Buncel et al. reported that nucleophilic substitution reactions of aryl acetates with phenoxide proceed through a stepwise mechanism, since $\sigma^{-}$constants exhibits much poorer Hammett correlation than $\sigma^{\circ}$ constants. ${ }^{4}$

Although $\mathrm{CN}^{-}$ion has been employed as an anionic carboncentered nucleophile in various organic syntheses, kinetic studies of $\mathrm{CN}^{-}$ion with carboxylic esters are lacking. ${ }^{5 \mathrm{a}-\mathrm{k}} \mathrm{We}$ have performed nucleophilic substitution reactions of 9 different Y-substituted phenyl benzoates (1) and thionobenzoates (2) with anionic nucleophiles such as $\mathrm{CN}^{-}, \mathrm{OH}^{-}$and $\mathrm{N}_{3}^{-6,7}$. Analysis of linear free energy relationships (e.g., Brønsted-type, Hammett and Yukawa-Tsuno plots) has led us to conclude that the reactions proceed through a stepwise mechanism with an addition intermediate. ${ }^{6,7}$ The rate-determining step (RDS) has been su-

\footnotetext{
${ }^{\dagger}$ This paper is dedicated to Professor Sunggak Kim on the occasion of his honorable retirement.
}

ggested to be formation of an intermediate for the reactions of 2 with $\mathrm{CN}^{-}$and $\mathrm{OH}^{-}$, while the RDS for the reaction with $\mathrm{N}_{3}{ }^{-}$ changes from breakdown of the intermediate to its formation as the leaving-group basicity decreases. ${ }^{6}$ A similar conclusion has been drawn for the reactions of 1 with $\mathrm{CN}^{-}, \mathrm{OH}^{-}$and $\mathrm{N}_{3}^{-}$, i.e., the RDS is formation of an addition intermediate for the reactions with $\mathrm{OH}^{-}$and $\mathrm{CN}^{-}$but breakdown of the intermediate for the reactions with $\mathrm{N}_{3}^{-}$.

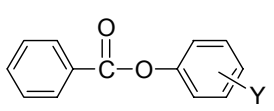

1

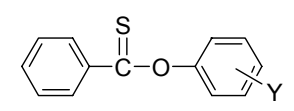

2
The evidence provided for a stepwise mechanism was mainly based on the fact that $\sigma^{\circ}$ constants result in better Hammett correlation than $\sigma^{-}$constants for the reactions of 9 different Ysubstituted phenyl benzoates with the anionic nucleophiles. ${ }^{7 \mathrm{a}}$ However, we have recently shown that deduction of reaction mechanism based just on Hammett correlation with $\sigma^{-}$or $\sigma^{\circ}$ constants can be misleading for alkaline hydrolysis and ethanolysis of Y-substituted phenyl diphenylphosphinates and diphenylthiophosphinates.

Thus, we have reinvestigated nucleophilic substitution reactions of 18 different Y-substituted phenyl benzoates (1a-r) with $\mathrm{CN}^{-}$(Scheme 1). The kinetic results have been compared with those reported previously for the reactions of $O$-Y-sub-

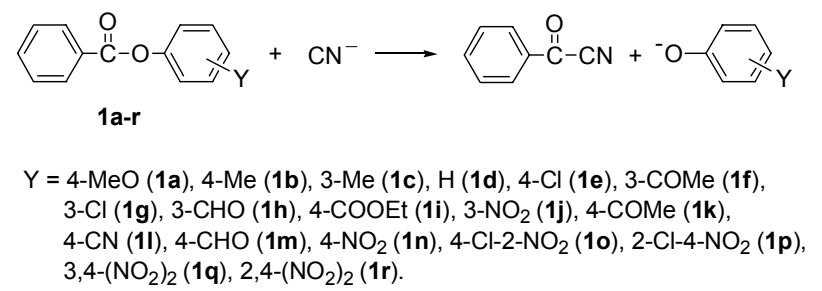

Scheme 1 
stituted phenyl thionobenzoates (2a-r, the thio analogues of 1a-r) with $\mathrm{CN}^{-}$to investigate the effect of modification of the electrophilic center from $\mathrm{C}=\mathrm{S}$ to $\mathrm{C}=\mathrm{O}$ on reactivity and mechanism.

\section{Results and Discussion}

The kinetic study was performed spectrophotometrically. All reactions proceeded with quantitative liberation of Y-substituted phenoxide ion (and/or its conjugate acid) under pseudo-firstorder conditions (i.e., the nucleophile concentration in excess over the substrate concentration). The reactions obeyed firstorder kinetics and pseudo-first-order rate constants $\left(k_{\mathrm{obsd}}\right)$ were determined from the equation, $\ln \left(A_{\infty}-A_{\mathrm{t}}\right)=-k_{\mathrm{obsd}} t+C$. Based on replicate runs, it is estimated that the uncertainty in the $k_{\text {obsd }}$ values is less than $\pm 3 \%$. Plots of $k_{\text {obsd }} v s$. [CN $\left.{ }^{-}\right]$were linear and passed through the origin, indicating that the contribution of water to $k_{\text {obsd }}$ is negligible. The second-order rate constants $\left(k_{\mathrm{CN}^{-}}\right)$were determined from the slopes of the linear plots. The $k_{\mathrm{CN}^{-}}$values determined in this way are summarized in Table 1 together with the $k_{\mathrm{CN}^{-}}$values reported previously for reactions of $O$-Y-substituted phenyl thionobenzoates $(\mathbf{2 a - q})^{6 \mathrm{~b}}$ to investigate the effect of changing the electrophilic center from $\mathrm{C}=\mathrm{O}$ to $\mathrm{C}=\mathrm{S}$ on reactivity of $\mathrm{CN}^{-}$.

Effect of changing electrophilic center from $\mathrm{C}=\mathrm{S}$ to $\mathrm{C}=\mathbf{O}$ on reactivity. Table 1 shows that the $k_{\mathrm{CN}^{-}}$value for the reactions of Y-substituted phenyl benzoates (1a-r) with $\mathrm{CN}^{-}$ion increases as the basicity of the leaving group decreases, e.g., it increases from $8.43 \times 10^{-3} \mathrm{M}^{-1} \mathrm{~s}^{-1}$ to $1.41 \times 10^{-1}$ and $1.22 \mathrm{M}^{-1} \mathrm{~s}^{-1}$ as the $\mathrm{p} K_{\mathrm{a}}$ of the conjugate acid of Y-substituted phenoxide decreases from

Table 1. Summary of second-order rate constants for reactions of Y-substituted phenyl benzoates (1) and thionobenzoates (2) with $\mathrm{CN}^{-}$ in $80 \mathrm{~mol} \% \mathrm{H}_{2} \mathrm{O} / 20 \mathrm{~mol} \% \mathrm{DMSO}$ at $25.0 \pm 0.1{ }^{\circ} \mathrm{C}^{a}$

\begin{tabular}{|c|c|c|c|c|}
\hline \multirow{2}{*}{ entry } & \multirow{2}{*}{$\mathrm{Y}$} & \multirow{2}{*}{$\mathrm{p} K_{\mathrm{a}}$} & \multicolumn{2}{|c|}{$10^{2} k_{\mathrm{CN}^{-}} / \mathrm{M}^{-1} \mathrm{~s}^{-1}$} \\
\hline & & & 1 & 2 \\
\hline $\mathbf{a}$ & 4-MeO & 10.20 & $0.843^{b}$ & 2.13 \\
\hline b & 4-Me & 10.19 & $0.783^{b}$ & 1.89 \\
\hline c & $3-\mathrm{CH}_{3}$ & 10.08 & 0.724 & - \\
\hline d & $\mathrm{H}$ & 9.95 & $1.02^{b}$ & 2.75 \\
\hline e & $4-\mathrm{Cl}$ & 9.38 & 2.32 & - \\
\hline f & 3-COMe & 9.19 & $3.59^{b}$ & - \\
\hline g & $3-\mathrm{Cl}$ & 9.02 & 4.19 & - \\
\hline h & $3-\mathrm{CHO}$ & 8.98 & 3.93 & - \\
\hline $\mathbf{i}$ & 4-COOEt & 8.50 & 6.07 & - \\
\hline $\mathbf{j}$ & $3-\mathrm{NO}_{2}$ & 8.35 & $14.1^{b}$ & 18.0 \\
\hline $\mathbf{k}$ & 4-COMe & 8.05 & $7.68^{b}$ & 7.88 \\
\hline I & $4-\mathrm{CN}$ & 7.95 & 14.6 & - \\
\hline $\mathbf{m}$ & 4-CHO & 7.66 & $10.3^{b}$ & 9.26 \\
\hline $\mathbf{n}$ & $4-\mathrm{NO}_{2}$ & 7.14 & $23.1^{b}$ & 19.7 \\
\hline $\mathbf{0}$ & $4-\mathrm{Cl}-2-\mathrm{NO}_{2}$ & 6.46 & 17.1 & - \\
\hline $\mathbf{p}$ & $2-\mathrm{Cl}-4-\mathrm{NO}_{2}$ & 5.45 & 48.2 & - \\
\hline $\mathbf{q}$ & $3,4-\left(\mathrm{NO}_{2}\right)_{2}$ & 5.42 & $192^{b}$ & 93.5 \\
\hline $\mathbf{r}$ & $2,4-\left(\mathrm{NO}_{2}\right)_{2}$ & 4.11 & 122 & - \\
\hline
\end{tabular}

${ }^{a}$ Data for reactions of Y-substituted phenyl thionobenzoates (2a-q) were taken from ref. $6 \mathrm{~b} .{ }^{b}$ Data taken from ref. $7 \mathrm{a}$.
10.20 to 8.35 and 4.11, in turn. A similar result is shown for the corresponding reactions of Y-substituted phenyl thionobenzoates (2a-q), although their relative reactivity is dependent on the basicity of the leaving aryloxide, e.g., aryl benzoates possessing a strongly basic leaving group (1a-k) are less reactive than the corresponding thionobenzoates (2a-k) but the opposite is true when the leaving groups are weakly basic, i.e., $\mathbf{1 m - q}$ are more reactive than $\mathbf{2} \mathbf{m}-\mathbf{q}$.

Modification of the electrophilic center from $\mathrm{C}=\mathrm{O}$ to $\mathrm{C}=\mathrm{S}$ (e.g., $1 \rightarrow 2$ ) has been reported to accompany a significant increase in polarizability. ${ }^{9-11}$ The enhanced polarizability of the $\mathrm{C}=\mathrm{S}$ bond in $\mathbf{2}$ is well reflected in the ${ }^{13} \mathrm{C}$ NMR chemical shift of the thiono carbonyl carbon, ${ }^{9,10}$ e.g., the chemical shifts have been reported to be 163.8 ppm for the carbonyl carbon in $\mathbf{1 n}$ and $209.8 \mathrm{ppm}$ for the thiocarbonyl carbon in $\mathbf{2 n}$, i.e., $46 \mathrm{ppm}$ down field shift in the ${ }^{13} \mathrm{C} N M R$. ${ }^{9 a}$

We have recently reported that the effect of changing the electrophilic center from $\mathrm{C}=\mathrm{O}$ to $\mathrm{C}=\mathrm{S}$ on reactivity is significant, e.g., $2 \mathrm{n}$ is over $10^{4}$ times more reactive than $\mathbf{1 n}$ toward polarizable 4-chlorothiophenoxide ion, while $c a$. 10 times less reactive toward nonpolarizable $\mathrm{OH}^{-}$ion. ${ }^{9 a}$ Azide ion $\left(\mathrm{N}_{3}{ }^{-}\right)$has also been found to be $4 \times 10^{3}$ times more reactive toward $2 \mathbf{n}$ than toward $1 \mathbf{n}^{6 \mathrm{~b}}$

The above results are consistent with the HSAB principle. ${ }^{12}$ Thus, one might expect that $\mathrm{CN}^{-}$ion would exhibit significantly enhanced reactivity toward polarizable thiono compounds $\mathbf{2 a - q}$ compared to their oxygen analogues $\mathbf{1 a - q}$, since $\mathrm{CN}^{-}$was classified as a soft base. ${ }^{13}$ However, Table 1 shows that the effect of changing the electrophilic center from $\mathrm{C}=\mathrm{O}$ to $\mathrm{C}=\mathrm{S}$ on reactivity of $\mathrm{CN}^{-}$ion is negligible. Furthermore, the fact that $\mathbf{2 m - q}$ are even less reactive than $\mathbf{1} \mathbf{m}-\mathbf{q}$ suggests that $\mathrm{CN}^{-}$might not be a soft base.

Effect of modification of $\mathbf{C}=\mathbf{S}$ to $\mathbf{C}=\mathbf{O}$ on mechanism. To investigate reaction mechanism, a Brønsted-type plot has been constructed. As shown in Figure 1, substrates 1o, 1p and 1r

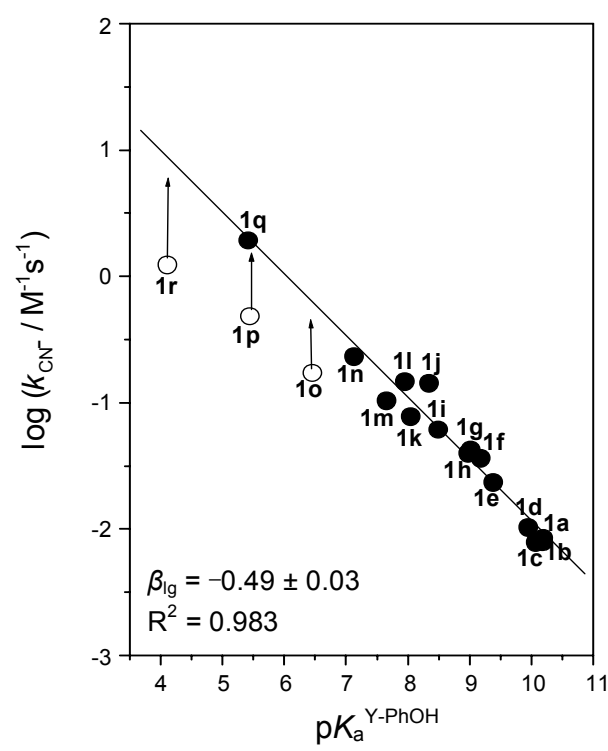

Figure 1. Brønsted-type plot for reactions of Y-substituted phenyl benzoates (1a-r) with $\mathrm{CN}^{-}$in $80 \mathrm{~mol}^{\circ} \mathrm{H}_{2} \mathrm{O} / 20 \mathrm{~mol} \% \mathrm{DMSO}$ at $25.0 \pm$ $0.1{ }^{\circ} \mathrm{C}$. The identity of points is given in Table 1 . 
deviate negatively from the linear Brønsted-type plot. A common feature of these substrates is possession of a substituent at 2-position of the leaving aryloxide. Thus, one can suggest that steric hindrance is responsible for the negative deviation. In fact, steric hindrance has been reported to be significant for aminolysis of esters with 2,4-dinitrophenoxide as a leaving group, e.g., 2,4-dinitrophenyl phenyl carbonate, ${ }^{14}$ benzoate, ${ }^{15 a}$ 2 -furoate, ${ }^{15 b}$ and thiophene-2-carboxylate. ${ }^{15 \mathrm{c}}$

The slope of the Brønsted-type plot $\left(\beta_{\mathrm{lg}}\right)$ shown in Figure 1 is -0.49 with $\mathrm{R}^{2}=0.983$ when the substrates possessing a substituent at 2-position of the leaving aryloxide (e.g., 1o, 1p and 1r) are excluded from the correlation. The $\beta_{\mathrm{g}}$ value of -0.49 is typical for reactions reported previously to proceed through a concerted mechanism. ${ }^{16-22}$ Accordingly, one can suggest that the reaction of 1a-q with $\mathrm{CN}^{-}$proceeds through a concerted pathway.

(A)

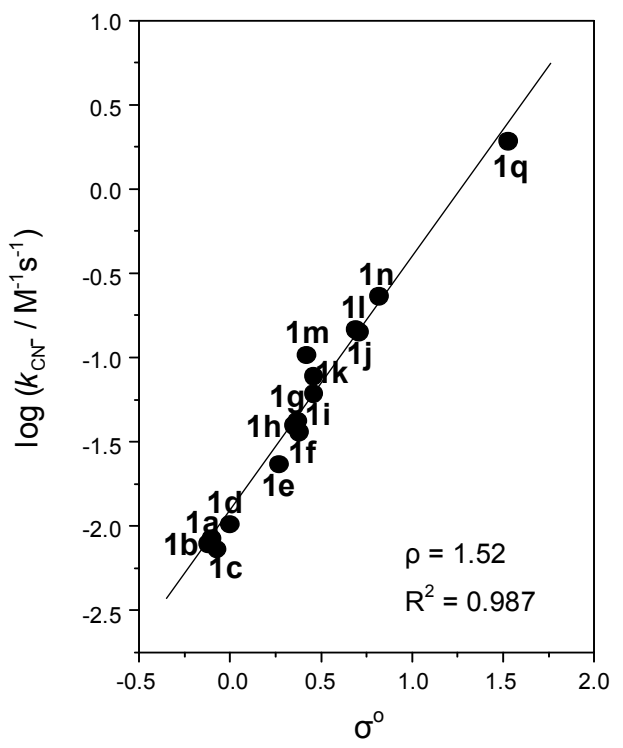

(B)

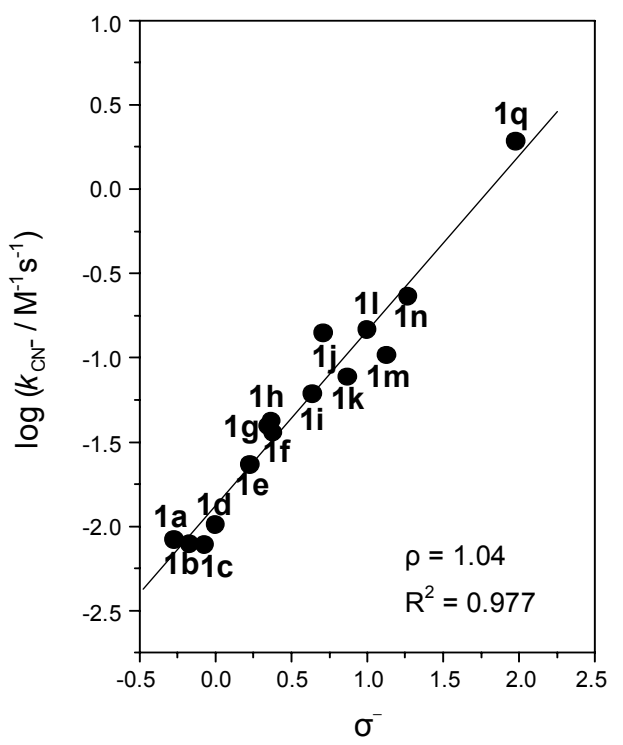

Figure 2. Hammett plots correlated with $\sigma^{\circ}(\mathrm{A})$ and $\sigma^{-}(\mathrm{B})$ constants for reactions of Y-substituted phenyl benzoates (1a-q) with $\mathrm{CN}^{-}$in $80 \mathrm{~mol} \% \mathrm{H}_{2} \mathrm{O} / 20 \mathrm{~mol} \% \mathrm{DMSO}$ at $25.0 \pm 0.1{ }^{\circ} \mathrm{C}$. The identity of points is given in Table 1 .
To examine the above idea, Hammett plots have been constructed using $\sigma^{\circ}$ and $\sigma^{-}$constants in Figure 2. One can expect that $\sigma^{-}$constants would exhibit a better correlation than $\sigma^{\circ}$ constants when leaving-group departure is involved in the RDS either in a stepwise mechanism or in a concerted pathway. This is because the negative charge developing on the oxygen atom of the leaving aryloxide can be delocalized on the substituent $Y$ through resonance interactions. In contrast, when expulsion of the leaving group occurs after the RDS, no negative charge would develop on the oxygen atom of the leaving group in the transition state of the RDS. In this case, $\sigma^{\circ}$ constants would result in a better correlation coefficient than $\sigma^{-}$constants. As shown in Figures $2 \mathrm{~A}$ and $2 \mathrm{~B}, \sigma^{\circ}$ constants result in a slightly better correlation coefficient than $\sigma^{-}$constants. However, both Hammett plots exhibit many scattered points. Thus, one cannot obtain any conclusive information on mechanism for the reactions of $\mathbf{1} \mathbf{a}-\mathbf{q}$ from the Hammett correlations.

Nonlinear Hammett plots have been reported for reactions of 2,4-dinitrophenyl X-substituted benzoates and related compounds with amines as well as with anionic nucleophiles such as $\mathrm{OH}^{-}, \mathrm{CN}^{-}$, and $\mathrm{N}_{3}^{-}$, e.g., the plots have been reported to exhibit a downward curvature as the substituent $\mathrm{X}$ in the benzoyl or thionobenzoyl moiety changes from electron-withdrawing groups to electron-donating ones. ${ }^{6,7}$ In contrast, the YukawaTsuno plot for the same reactions exhibited an excellent linear correlation with a positive slope. ${ }^{6,7}$ Thus, it has been concluded that the nonlinear Hammett plots are not due to a change in RDS but are caused by ground-state (GS) stabilization through resonance interactions as illustrated resonance structures I $\leftrightarrow$ II. $^{6,7}$

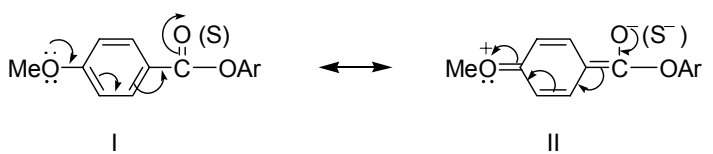

A Yukawa-Tsuno plot for the reactions of $\mathbf{1 a - q}$ with $\mathrm{CN}^{-}$has been constructed to obtain further information on mechanism. As shown in Figure 3, the Yukawa-Tsuno plot exhibits excellent linearity $\left(\mathrm{R}^{2}=0.996\right)$ with $\rho=1.37$ and $r=0.34$. The $r$ value in the Yukawa-Tsuno equation (eq 1) represents the extent of resonance contribution between the reaction site and substituent $\mathrm{Y}^{23,24}$ Since eq (1) becomes the Hammett equation when $r=0$ or 1 , the fact that $r$ is neither 0 nor 1 is consistent with the fact that $\sigma^{\circ}$ and $\sigma^{-}$constants result in poor correlation coefficients as shown in Figure 2.

$$
\log k^{\mathrm{Y}} / k^{\mathrm{H}}=\rho\left(\sigma^{\mathrm{o}}+r\left(\sigma^{-}-\sigma^{\mathrm{o}}\right)\right)
$$

The $r$ value of 0.34 implies that a negative charge develops partially on the oxygen atom of the leaving aryloxide. Thus, one can suggest that expulsion of the leaving group occurs in the RDS. In this case, two different mechanisms are possible, i.e., a concerted mechanism and a stepwise pathway in which expulsion of the leaving group occurs in the RDS. However, one can exclude a stepwise mechanism. This is because the $\rho$ value should be much larger than 1.37, if the reaction proceeds through a stepwise mechanism, in which breakdown of the 


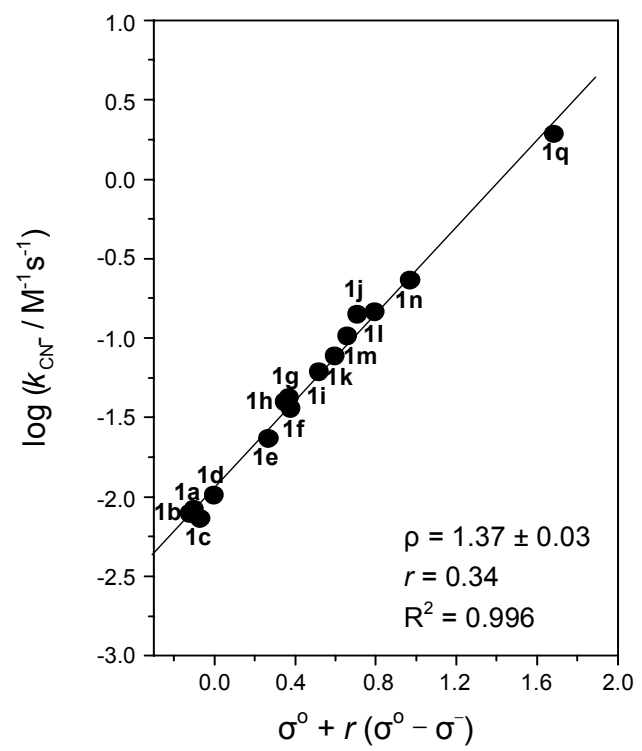

Figure 3. Yukawa-Tsuno plot for reactions of Y-substituted phenyl benzoates (1a-q) with $\mathrm{CN}^{-}$in $80 \mathrm{~mol} \% \mathrm{H}_{2} \mathrm{O} / 20 \mathrm{~mol} \%$ DMSO at $25.0 \pm 0.1{ }^{\circ} \mathrm{C}$. The identity of points is given in Table 1 .

intermediate occurs in the RDS. In fact, the reactions of 1a-q with $\mathrm{N}_{3}{ }^{-}$resulted in a $\rho_{Y}$ value of 2.45 and were suggested to proceed through an intermediate with its breakdown being the $\mathrm{RDS}^{7 \mathrm{c}}$ On the contrary, we have recently reported that the reactions of 2a-q with $\mathrm{CN}^{-}$proceed through a stepwise mechanism, in which expulsion of the leaving group occurs after the RDS on the basis of the fact that (1) $\sigma^{\circ}$ constants result in much better Hammett correlation than $\sigma^{-}$constants and (2) the $\rho_{Y}$ value is fairly small (1.02). ${ }^{6 \mathrm{~b}}$ Thus, the fact that the Yukawa-Tsuno plot is linear with $\rho_{\mathrm{Y}}=1.37$ and $r=0.34$ is consistent with the preceding proposal that the reactions of $1 \mathrm{a}-\mathrm{r}$ with $\mathrm{CN}^{-}$proceed through a concerted mechanism on the basis of $\beta_{\mathrm{lg}}=-0.49$.

\section{Conclusions}

(1) Aryl benzoates possessing a strongly basic leaving group (1a-k) are less reactive than the corresponding thionobenzoates (2a-k) toward $\mathrm{CN}^{-}$ion but aryl benzoates with a weakly basic leaving group (e.g., 1 $\mathbf{m}-\mathbf{q})$ are more reactive than the corresponding thionobenzoates 2m-q. (2) The Brønsted-type plot is linear with $\beta_{\mathrm{lg}}=-0.49$ when the substrates possessing a substituent at 2-position of the leaving aryloxide are excluded in the correlation. (3) Hammett plots correlated with $\sigma^{-}$and $\sigma^{\circ}$ constants exhibit many scattered points, while the corresponding Yukawa-Tsuno plot results in excellent correlation with $\rho_{\mathrm{Y}}=$ 1.37 and $r=0.34$, indicating that expulsion of the leaving group occurs in the RDS. (4) The current reactions proceed through a concerted mechanism on the basis of the magnitude of the $\beta_{\mathrm{lg}}$ and $\rho_{\mathrm{Y}}$ values.

\section{Experimental Section}

Materials. Y-Substituted phenyl benzoates (1a-r) were synthesized by treating Y-substituted phenol with benzoyl chloride in anhydrous ether in the presence of triethylamine, and purified through column chromatography. Their purity was confirmed by their melting points and ${ }^{1} \mathrm{H}$ NMR spectra. DMSO and other chemicals were of the highest quality available. Doubly glassdistilled water was further boiled and cooled under nitrogen just before use to remove dissolved $\mathrm{CO}_{2}$.

Kinetics. The kinetic study was performed using a UV-vis spectrophotometer equipped with a constant temperature circulating bath. The reactions were followed by monitoring the appearance of Y-substituted phenoxide at a fixed wavelength corresponding the maximum absorption. Due to low solubility of substrates 1a-r in pure water, reactions were carried out in $80 \mathrm{~mol} \% \mathrm{H}_{2} \mathrm{O} / 20 \mathrm{~mol} \%$ DMSO. Typically, the reaction was initiated by adding $5 \mu \mathrm{L}$ of a $0.02 \mathrm{M}$ of substrate stock solution in $\mathrm{MeCN}$ by a $10 \mu \mathrm{L}$ syringe to a $10 \mathrm{~mm} \mathrm{UV}$ cell containing $2.50 \mathrm{~mL}$ of the reaction medium and nucleophile. The KCN stock solution of $\mathrm{ca} .0 .2 \mathrm{M}$ was prepared in $25.0 \mathrm{~mL}$ volumetric flask under nitrogen. Transfers of solutions were carried out by means of gas-tight syringes. All reactions were carried out under pseudo-first-order conditions in which nucleophile concentrations were at least 30 times greater than the substrate concentration.

Product analysis. Y-Substituted phenoxide was identified as one of the products by comparison of the UV-vis spectra at the end of the reactions with the authentic samples under the same reaction conditions.

Acknowledgments. This research was supported by Basic Science Research Program through the National Research Foundation of Korea (NRF) funded by the Ministry of Education, Science and Technology (2009-0075488). E. H. Kim and S. I. Kim are also grateful for the BK 21 Scholarship.

\section{References}

1. (a) Jencks, W. P. Chem. Rev. 1985, 85, 511-527. (b) Page, M. I.; Williams, A. Organic and Bio-organic Mechanisms; Longman: Harlow, U. K., 1997; Chapter 7. (c) Castro, E. A. Chem. Rev. 1999, 99, 3505-3524. (d) Lee, I.; Sung, D. D. Curr. Org. Chem. 2004, 8, 557-567. (e) Menger, F. M.; Smith, J. H. J. J. Am. Chem. Soc. 1972, 94, 3824-3829.

2. (a) Williams, A. Acc. Chem. Res. 1989, 22, 387-392. (b) Ba-Saif, S.; Luthra, A. K.; Williams, A. J. Am. Chem. Soc. 1987, 109, 63626368.

3. (a) Stefanidis, D.; Cho, S.; Dhe-Paganon, S.; Jencks, W. P. J. Am. Chem. Soc. 1993, 115, 1650-1656. (b) Andres, G. O.; Granados, A. M.; Rossi, R. H. J. Org. Chem. 2001, 66, 7653-7657. (c) Castro, E. A.; Angel, M.; Arellano, D.; Santos, J. G. J. Org. Chem. 2001, 66, 6571-6575. (d) Hess, R. A.; Hengge, A. C.; Cleland, W. W. J. Am. Chem. Soc. 1997, 119, 6980-6983. (e) Guthrie, J. P. J. Am. Chem. Soc. 1996, 118, 12878-12885.

4. (a) Buncel, E.; Um, I. H.; Hoz, S. J. Am. Chem. Soc. 1989, 111, 971-975. (b) Pregel, M.; Dunn, E. J.; Buncel, E. J. Am. Chem. Soc. 1991, 113, 3545-3550.

5. (a) Wubbels, G. G.; Brown, T. R.; Babcock, T. A.; Johnson, K. M. J. Org. Chem. 2008, 73, 1925-1934. (b) Tumanov, V. V.; Tishkov, A. A.; Mayr, H. Angew. Chem., Int. Ed. 2007, 46, 3563-3566. (c) Almerindo, G. I.; Pliego, J. R. Chem. Phys. Lett. 2006, 423, 459462. (d) Fang, Y.; MacMillar, S.; Eriksson, J.; Kolodziejska-Huben, M.; Dybala-Defratyka, A.; Paneth, P.; Matsson, O.; Westaway, K. C. J. Org. Chem. 2006, 71, 4742-4747. (e) Park, G.; Kim, S. C.; Kang, H. Y. Bull. Korean Chem. Soc. 2005, 26, 1339-1343. (f) Almerindo, G. I.; Pliego, J. R., Jr. Org. Lett. 2005, 7, 1821-1823. (g) Minegishi, S.; Mayr, H. J. Am. Chem. Soc. 2003, 125, 286-295. 
(h) Westaway, K. C.; Fang, Y. R.; Persson, J.; Matsson, O. J. Am. Chem. Soc. 1998, 120, 3340-3344. (i) Matsson, O.; Persson, J.; Axelsson, B. S.; Laangstroem, B.; Fang, Y.; Westaway, K. C. J. Am. Chem. Soc. 1996, 118, 6350-6354. (j) Richard, J. P.; Jencks, W. P. J. Am. Chem. Soc. 1984, 106, 1383-1396. (k) Ritchie, C. D.; VanVerth, J. E.; Virtanen, P. O. I. J. Am. Chem. Soc. 1982, 104, 3491-3497.

6. (a) Um, I. H.; Lee, J. Y.; Kim, H. T.; Bae, S. K. J. Org. Chem. 2004, 69, 2436-2441. (b) Um, I. H.; Kim, E. H.; Lee, J. Y. J. Org. Chem. 2009, 74, 1212-1217

7. (a) Um, I. H.; Lee, J. Y.; Fujio, M.; Tsuno, Y. Org. Biomol. Chem. 2006, 4, 2979-2985. (b) Um, I. H.; Han, H. J.; Ahn, J. A.; Kang, S.; Buncel, E. J. Org. Chem. 2002, 67, 8475-8480. (c) Um, I. H.; Kim, E. H.; Han, H. J. Bull. Korean Chem. Soc. 2008, 29, 580-584.

8. (a) Um, I. H.; Han, J. Y.; Hwang, S. J. Chem. Eur. J. 2008, 14, 7324-7330. (b) Um, I. H.; Park, J. E.; Shin, Y. H. Org. Biomol. Chem. 2007, 5, 3539-3543.

9. (a) Um, I. H.; Lee, J. Y.; Bae, S. Y.; Buncel, E. Can. J. Chem. 2005, 83, 1365-1371. (b) Um, I. H.; Han, J. Y.; Buncel, E. Chem. Eur. J. 2009, 15, 1011-1017.

10. (a) Middleton, W. J.; Howard, E. G.; Sharkey, W. H. J. Org. Chem. 1965, 30, 1375-1384. (b) Pedersen, B. S.; Scheibye, S.; Nilsson, N. H.; Lawesson, S. O. Bull. Soc. Chim. Belg. 1978, 87, 223-228. (c) Harris, J. F.; Stacey, F. W. J. Am. Chem. Soc. 1963, 85, 749-754.

11. (a) Um, I. H.; Lee, S. E.; Kwon, H. J. J. Org. Chem. 2002, 67, 8999-9005. (b) Um, I. H.; Han, H. J.; Baek, M. H.; Bae, S. Y. J. Org. Chem. 2004, 69, 6365-6370. (c) Um, I. H.; Kim, E. Y.; Park, H. R.; Jeon, S. E. J. Org. Chem. 2006, 71, 2302-2306. (d) Um, I. H.; Hwang, S. J.; Baek, M. H.; Park, E. J. J. Org. Chem. 2006, 71, 9191-9197. (e) Um, I. H.; Yoon, S.; Park, H. R.; Han, H. J. Org. Biomol. Chem. 2008, 6, 1618-1624. (f) Um, I. H.; Hwang, S. J.; Yoon, S.; Jeon, S. E.; Bae, S. K. J. Org. Chem. 2008, 73, 7671-7677.

12. Ho, T. L. In Hard and soft acid and bases; Pearson, R. G. Ed.; Academic Press: New York, 1977.

13. Jones, R. A. Y. Physical and mechanistic organic chemistry; 2nd ed.; Cambridge University Press: London, 1984; pp 135-137.

14. Gresser, M. J.; Jencks, W. P. J. Am. Chem. Soc. 1977, 99, 69636970.

15. (a) Um, I. H.; Seo, J. A.; Lee, H. M. Bull. Korean Chem. Soc. 2008, 29, 1915-1919. (b) Um, I. H.; Akhtar, K. Bull. Korean Chem. Soc. 2008, 29, 772-776. (c) Um, I. H.; Seo, J. A.; Chun, S. M. Bull. Korean Chem. Soc. 2008, 29, 1459-1463.

16. (a) Um, I. H.; Shin, Y. H.; Han, J. Y.; Mishima, M. J. Org. Chem. 2006, 71, 7715-7720. (b) Um, I. H.; Han, J. Y.; Shin, Y. H. J. Org. Chem. 2009, 74, 3073-3078.

17. (a) Bourne, N.; Chrystiuk, E.; Davis, A. M.; Williams, A. J. Am. Chem. Soc. 1988, 110, 1890-1895. (b) Douglas, K. T.; Williams, A. J. Chem. Soc., Perkin Trans. 2 1976, 515-521.

18. Younker, J. M.; Hengge, A. C. J. Org. Chem. 2004, 69, 9043-9048.

19. (a) Castro, E. A.; Pavez, P.; Santos, J. G. J. Org. Chem. 2001, 66, 3129-3132. (b) Castro, E. A.; Angel, M.; Arellano, D.; Santos, J. G. J. Org. Chem. 2001, 66, 6571-6575. (c) Castro, E. A.; Angel, M.; Pavez, P.; Santos, J. G. J. Chem. Soc., Perkin Trans. 2 2001, $12,2351-2354$

20. Um, I. H.; Han, J. Y.; Hwang, S. J. Chem. Eur. J. 2008, 14, 73247330

21. Um, I. H.; Park, J. E.; Shin, Y. H. Org. Biomol. Chem. 2007, 5, 3539-3543.

22. Oh, H. K.; Jin, Y. C.; Sung, D. D.; Lee, I. Org. Biomol. Chem. 2005, 3, 1240-1244.

23. (a) Yukawa, Y.; Tsuno, Y. Bull. Chem. Soc. Jpn. 1959, 32, 965-970. (b) Tsuno, Y.; Fujio, M. Chem. Soc. Rev. 1996, 25, 129-139. (c) Tsuno, Y.; Fujio, M. Adv. Phys. Org. Chem. 1999, 32, 267-385.

24. (a) Nakata, K.; Fujio, M.; Nishimoto, K.; Tsuno, Y. J. Phys. Org. Chem. 2003, 16, 323-335. (b) Fujio, M.; Rappoport, Z.; Uddin, H. J.; Kim, H. J.; Tsuno, Y. Bull. Chem. Soc. Jpn. 2003, 76, 163-169. (c) Fujio, M.; Uchida, M.; Okada, A.; Alam, M. A.; Fujiyama, R.; Siehl, H. U.; Tsuno, Y. Bull. Chem. Soc. Jpn. 2005, 78, 1834-1842. (d) Fujio, M.; Umezaki, Y.; Alam, M. A.; Kikukawa, K.; Fujiyama, R.; Tsuno, Y. Bull. Chem. Soc. Jpn. 2006, 79, 1091-1099. 